\title{
Impact of Lipoprotein (a) Levels on Long-Term Outcomes in Patients With Coronary Artery Disease and Left Ventricular Systolic Dysfunction
}

Jun Shitara, MD; Takatoshi Kasai, MD, PhD; Hirokazu Konishi, MD, PhD; Hirohisa Endo, MD; Hideki Wada, MD, PhD; Shinichiro Doi, MD, PhD; Ryo Naito, MD, PhD; Shuta Tsuboi, MD, PhD; Manabu Ogita, MD, PhD; Tomotaka Dohi, MD, PhD; Shinya Okazaki, MD; Katsumi Miyauchi, MD; Hiroyuki Daida, MD

Background: Serum levels of lipoprotein (a) ( $L p(a))$ could be a risk factor for adverse events in patients with coronary artery disease (CAD). However, the effect of $L p(a)$ on long-term outcomes in patients with left ventricular (LV) systolic dysfunction, possibly through the increased likelihood for development of heart failure (HF), remains to be elucidated. This study aimed to determine the prognostic impact of $L p(a)$ in patients with CAD and LV systolic dysfunction.

Methods and Results: A total of 3,508 patients who underwent percutaneous coronary intervention were candidates. We analyzed 369 patients with LV systolic dysfunction (defined as LV ejection fraction $<50 \%$ ). They were assigned to groups according to a median level of $L p(a)$ (i.e., high $L p(a), \geq 21.6 \mathrm{mg} / \mathrm{dL}, \mathrm{n}=185$; low $L p(a),<21.6 \mathrm{mg} / \mathrm{dL}, \mathrm{n}=184$ ). The primary outcome was a composite of allcause death and readmission for acute coronary syndrome and/or HF. The median follow-up period was 5.1 years. Cumulative event-free survival was significantly worse for the group with high $L p(a)$ than for the group with low $L p(a)(P=0.005)$. In the multivariable analysis, a high $L p(a)$ level was an independent predictor of the primary outcomes (hazard ratio, 1.54; 95\% confidence interval, 1.09-2.18; $P=0.014)$.

Conclusions: A high $\mathrm{Lp}(\mathrm{a})$ value could be associated with long-term adverse clinical outcomes among patients with CAD and LV systolic dysfunction.

Key Words: Heart failure with reduced ejection fraction; Ischemic cardiomyopathy; Lipoprotein (a)

$\mathbf{W}$ ith the aging of society, the incidence and prevalence of heart failure (HF) continue to rise. ${ }^{1}$ In addition, recent advances in treatments of coronary artery disease (CAD) can prolong the patient's life and consequently, increase the likelihood of developing HF. ${ }^{2-4}$ In such patients, coexisting left ventricular (LV) systolic dysfunction is a particularly important determinant of clinical outcome, possibly through the increased likelihood of developing HF., Similarly, survivors of severe CAD with LV systolic dysfunction have a relatively high incidence of subsequent hospitalization for $\mathrm{HF}$, which is associated with significantly increased mortality. ${ }^{78} \mathrm{~A}$ registry of Japanese patients with acute coronary syndrome (ACS) also showed that those with a history of myocardial infarction (MI) have an increased risk of death, ${ }^{9}$ suggesting that recurrence of severe $\mathrm{CAD}$, such as ACS, worsens long-

\begin{abstract}
Editorial p 967
term clinical outcome partially because of the increased likelihood of incident $\mathrm{HF}$ in patients with $\mathrm{CAD}$ who might have LV systolic dysfunction caused by a previous MI. Therefore, identifying the risk factors for incident ACS and/or incident HF in addition to the all-cause death is important to improve the clinical outcomes of patients with CAD and LV systolic dysfunction.

One such risk factor may be lipoprotein (a) (Lp(a)), which is a low-density lipoprotein (LDL)-like particle with apolipoprotein (apo) B-100, linked by a disulfide bond to apolipoprotein (a). ${ }^{10}$ Increased levels of $\mathrm{Lp}(\mathrm{a})$ are an independent risk factor for cardiovascular disease; ${ }^{11,12}$ more specifically, aortic valve stenosis (AS), ${ }^{13,14}$ which is well recognized as a
\end{abstract}

Received September 18, 2018; revised manuscript received January 21, 2019; accepted February 12, 2019; J-STAGE Advance Publication released online March 26, 2019 Time for primary review: 42 days

Department of Cardiovascular Medicine (J.S., T.K., H.E., S.D., T.D., S.O., K.M., H.D.), Cardiovascular Respiratory Sleep Medicine (T.K.), Juntendo University Graduate School of Medicine, Tokyo; Sleep and Sleep Disordered Breathing Center, Juntendo University Hospital, Tokyo (T.K.); Department of Cardiology, Juntendo University Shizuoka Hospital, Izunokuni (H.K. H.W., S.T., M.O.); and Department of Cardiovascular Medicine, Juntendo University Urayasu Hospital, Urayasu (R.N.), Japan

Mailing address: Takatoshi Kasai, MD, PhD, Department of Cardiovascular Medicine, Juntendo University Graduate School of Medicine, 2-1-1 Hongo, Bunkyo-ku, Tokyo 113-8421, Japan. E-mail: kasai-t@mx6.nisiq.net

ISSN-1346-9843 All rights are reserved to the Japanese Circulation Society. For permissions, please e-mail: cj@j-circ.or.jp 


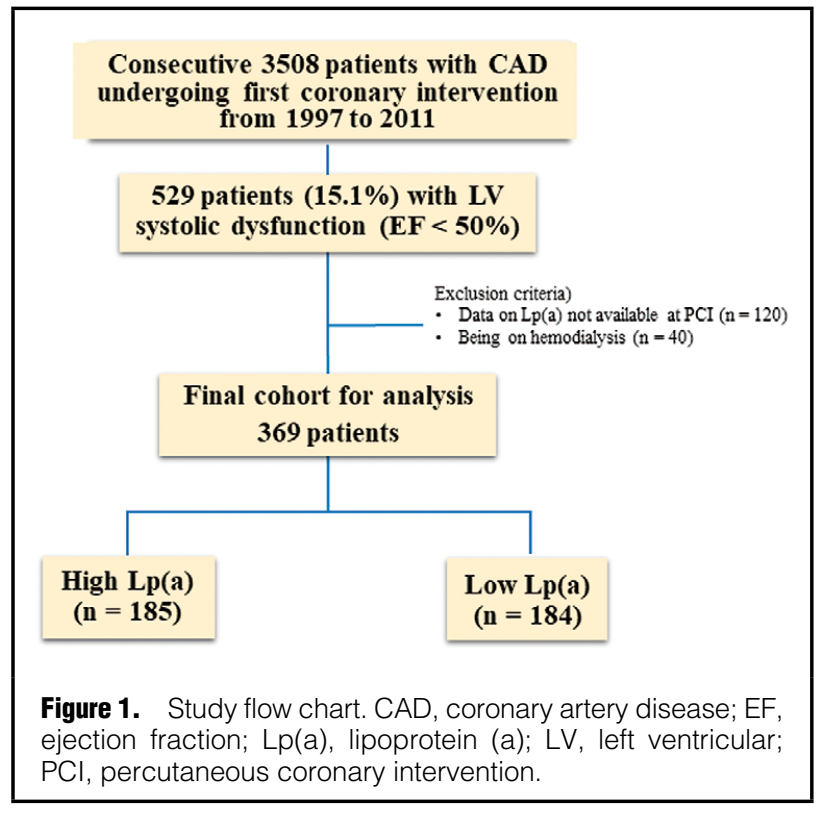

major cause of HF. A recent study conducted in a general population showed the relationship between $\mathrm{Lp}$ (a) levels and risk of incident HF. ${ }^{15}$ In patients with CAD, Lp(a) could be an important risk factor for long-term death and incident ACS independent of other traditional risk factors. ${ }^{16}$ Therefore, in patients with CAD and LV systolic dysfunction, higher levels of $\mathrm{Lp}$ (a) could be associated with a greater risk of death, incident HF, and ACS (as a predisposing condition for HF). However, no data are available regarding the relationship between $\mathrm{Lp}$ (a) levels and clinical outcomes in patients with CAD and LV systolic dysfunction. This study aimed to determine the impact of $\mathrm{Lp}(\mathrm{a})$ on long-term outcomes, including all-cause death, incident ACS, and HF, in patients with CAD and LV systolic dysfunction.

\section{Methods}

\section{Subjects}

We used the data from an observational cohort comprising consecutive patients who underwent percutaneous coronary intervention (PCI) at Juntendo University Hospital (Tokyo, Japan) between January 1997 and October 2011. Of them, we analyzed data from patients whose $\mathrm{LV}$ ejection fraction (LVEF) was $<50 \%$ at the time of PCI. Patients with missing Lp(a) data and those on dialysis were excluded, because Lp(a) plasma levels are obviously increased in such patients owing to kidney dysfunction. ${ }^{17}$ The patients were divided into 2 groups (high or low $\mathrm{Lp}(\mathrm{a})$ ) according to a median Lp(a) level of $21.6 \mathrm{mg} / \mathrm{dL}$ (Figure 1).

Informed consent was given by all patients before undergoing PCI. This study proceeded under the approval of the Juntendo University Hospital review board in accordance with the Declaration of Helsinki.

\section{Data Collection}

Baseline data of the patients' age, sex, body mass index (BMI), blood pressure (BP), smoking status, family history of CAD, blood tests, medication use, and comorbidities were prospectively collected. Blood samples were collected early in the morning of the PCI after an overnight fast in elective cases, whereas for patients with ACS, blood samples were obtained early in the morning of the next day after an overnight fast within $24 \mathrm{~h}$ after an emergency PCI. Hypertension was defined as systolic $\mathrm{BP} \geq 140 \mathrm{mmHg}$, diastolic $\mathrm{BP} \geq 90 \mathrm{mmHg}$, or medication with antihypertensive drugs. Diabetes mellitus was defined as fasting plasma glycemic levels $\geq 126 \mathrm{mg} / \mathrm{dL}$, medication with oral hypoglycemic drugs, or insulin injections. A current smoker was defined as a person who smoked at the time of PCI or who had quit smoking within the year before PCI. The presence of AS was defined as having at least a mild AS on echocardiography at the time of PCI. Chronic kidney disease (CKD) was defined as an estimated glomerular filtration rate (eGFR) of $<60 \mathrm{~mL} / \mathrm{min} / 1.73 \mathrm{~m}^{2}$, which was calculated based on the Modification of Diet in Renal Disease equation modified with a Japanese coefficient using baseline serum creatinine. ${ }^{18}$ Plasma Lp(a) levels were measured using latex agglutination immunoassays (Special Reference Laboratories, Hachioji, Tokyo, Japan).

\section{Outcomes}

The follow-up period ended on 31 December 2011. Survival data and information about hospital admissions were collected by serial contact with the patients or their families and assessed from the medical records of patients who had died or those who were followed up at Juntendo University Hospital. Details of hospital admission and the cause of death were supplied by other hospitals or clinics where the patients had been admitted. All data were collected by blinded investigators.

The primary outcomes of this study were composite events of all-cause death and unplanned readmission for non-fatal ACS or HF. We defined ACS as ST-elevation myocardial infarction (STEMI), non-STEMI, or unstable angina pectoris (UAP). We determined STEMI based on symptoms of ischemia with ST-segment elevation on ECG and increased serum levels of cardiac enzymes (troponin, CK-MB, CK $\geq 2$-fold increase), ${ }^{\mathbf{1 9 , 2 0}}$ and non-STEMI, based on symptoms of ischemia without ST-segment elevation on ECG and increased serum levels of cardiac enzymes. UAP was based on symptoms of ischemia at rest or having a crescendo of symptoms or new-onset symptoms associated with transient ischemic ST-segment shifts and normal serum levels of cardiac enzymes. ${ }^{21} \mathrm{HF}$ was defined as newonset or worsening signs and symptoms of HF that required urgent therapy and resulted in hospitalization. ${ }^{22}$

\section{Statistical Analysis}

The results are expressed as mean $\pm \mathrm{SD}$ or medians (interquartile range) for continuous variables and as a ratio (\%) for categorical variables. Baseline data were compared using an unpaired t-test or Mann-Whitney U test for continuous variables and the chi-squared test or Fisher's exact test for categorical variables. Kaplan-Meier event-free survival curves were compared using the log-rank test. Factors associated with outcomes were determined using univariable Cox regression analyses with the following variables: age, sex, BMI, family history, diabetes mellitus, hypertension, current smoking status, CKD, LDL-C, high-density lipoprotein cholesterol (HDL-C), triglycerides, use of medications, systolic and diastolic BP, LVEF, multivessel disease, presence of left main trunk lesion, presence of AS, and presentation of ACS in addition to the Lp(a) level (high or low). Variables with a P-value $<0.1$ in the univari- 


\begin{tabular}{|c|c|c|c|}
\hline & $\begin{array}{l}\text { High Lp(a) group } \\
(n=185)\end{array}$ & $\begin{array}{l}\text { Low Lp(a) group } \\
(n=184)\end{array}$ & $P$ value \\
\hline Age (years) & $65.3 \pm 11.5$ & $65.2 \pm 12.0$ & 0.969 \\
\hline Men (\%) & $158(85.4)$ & $162(88.0)$ & 0.455 \\
\hline BMI $\left(\mathrm{kg} / \mathrm{m}^{2}\right)$ & $23.7 \pm 3.7$ & $24.3 \pm 4.0$ & 0.180 \\
\hline Hypertension, n (\%) & $118(63.8)$ & $130(70.7)$ & 0.160 \\
\hline Diabetes mellitus, $\mathrm{n}(\%)$ & $90(48.7)$ & $75(40.8)$ & 0.127 \\
\hline CKD, n (\%) & $61(33.9)$ & $55(30.7)$ & 0.522 \\
\hline Family history of CAD, $\mathrm{n}(\%)$ & $52(28.1)$ & $47(25.5)$ & 0.578 \\
\hline Current smoking, n (\%) & $50(27.0)$ & $52(28.3)$ & 0.791 \\
\hline LDL-C, mg/dL & $119.5 \pm 34.1$ & $108.7 \pm 31.8$ & $<0.001$ \\
\hline $\mathrm{HDL}-\mathrm{C}, \mathrm{mg} / \mathrm{dL}$ & $43.3 \pm 12.6$ & $42.6 \pm 10.5$ & 0.592 \\
\hline Triglycerides, $\mathrm{mg} / \mathrm{dL}$ & $122.3 \pm 61.1$ & $125.9 \pm 70.4$ & 0.599 \\
\hline $\mathrm{Lp}(\mathrm{a}), \mathrm{mg} / \mathrm{dL}$ & $43.5 \pm 22.2$ & $12.0 \pm 5.5$ & $<0.001$ \\
\hline Systolic BP, mmHg & $130.6 \pm 23.4$ & $131.3 \pm 23.6$ & 0.758 \\
\hline Diastolic BP, mmHg & $72.3 \pm 13.9$ & $73.0 \pm 14.5$ & 0.608 \\
\hline LVEF, \% & $39.1 \pm 8.2$ & $40.3 \pm 7.7$ & 0.167 \\
\hline Aortic valve stenosis, $\mathrm{n}(\%)$ & $9(4.8)$ & $5(2.7)$ & 0.277 \\
\hline Multivessel disease, $\mathrm{n}(\%)$ & $115(62.2)$ & $115(62.5)$ & 0.946 \\
\hline Presentation of ACS, n (\%) & $79(42.7)$ & $85(46.2)$ & 0.499 \\
\hline LMT lesion, n (\%) & $3(1.6)$ & $1(0.5)$ & 0.306 \\
\hline \multicolumn{4}{|l|}{ Medications } \\
\hline Aspirin, n (\%) & $165(90.2)$ & $167(91.3)$ & 0.451 \\
\hline$\beta$-blocker, $\mathrm{n}(\%)$ & $96(53.0)$ & $87(48.3)$ & 0.371 \\
\hline Calcium-channel blocker, n (\%) & $35(19.2)$ & $38(20.8)$ & 0.543 \\
\hline ACEI/ARB, n (\%) & $123(67.6)$ & $132(73.3)$ & 0.230 \\
\hline Statins, n (\%) & $102(55.7)$ & $93(51.4)$ & 0.405 \\
\hline
\end{tabular}

$\mathrm{ACEl}$, angiotensin-converting enzyme inhibitor; ACS, acute coronary syndrome; ARB, angiotensin receptor blocker; $\mathrm{BMI}$, body mass index; BP, blood pressure; CAD, coronary artery disease; CKD, chronic kidney disease; HDL-C, high-density lipoprotein cholesterol; LDL-C, low-density lipoprotein cholesterol; LMT, left main trunk; Lp(a), lipoprotein(a); LVEF, left ventricular ejection fraction.

able analyses were included in the multivariable Cox regression analysis. The assumption of proportional hazards was assessed using a log-minus-log survival graph. Because Lp(a) levels may differ between patients presenting with and without ACS in association with differences in blood sampling timing, we performed a subgroup analysis regarding the presentation of ACS. The first-order interactions in the multivariable Cox proportional hazard models were examined by entering the interaction terms between the Lp(a) level and the presentation of ACS. We also determined the effect of $L p(a)$ levels on the clinical events in each subgroup. To determine whether the results differed with the cutoff points, we performed secondary analyses in which $L p(a)$ levels were treated as a natural logarithmtransformed continuous variable. $\mathrm{P}<0.05$ was considered to indicate significance, unless otherwise indicated. All data were analyzed using JMP 10.0 MDSU statistical software (SAS Institute, Cary, NC, USA).

\section{Results}

Figure 1 is a flow chart of the study population. We initially selected 529 patients with LV systolic dysfunction (EF $<50 \%$ ) among 3,508 patients who underwent PCI. Patients on dialysis $(n=40)$ and those with missing $\mathrm{Lp}(\mathrm{a})$ data at the time of PCI $(n=120)$ were excluded. Finally, 369 patients were enrolled and assigned to 2 groups according to the

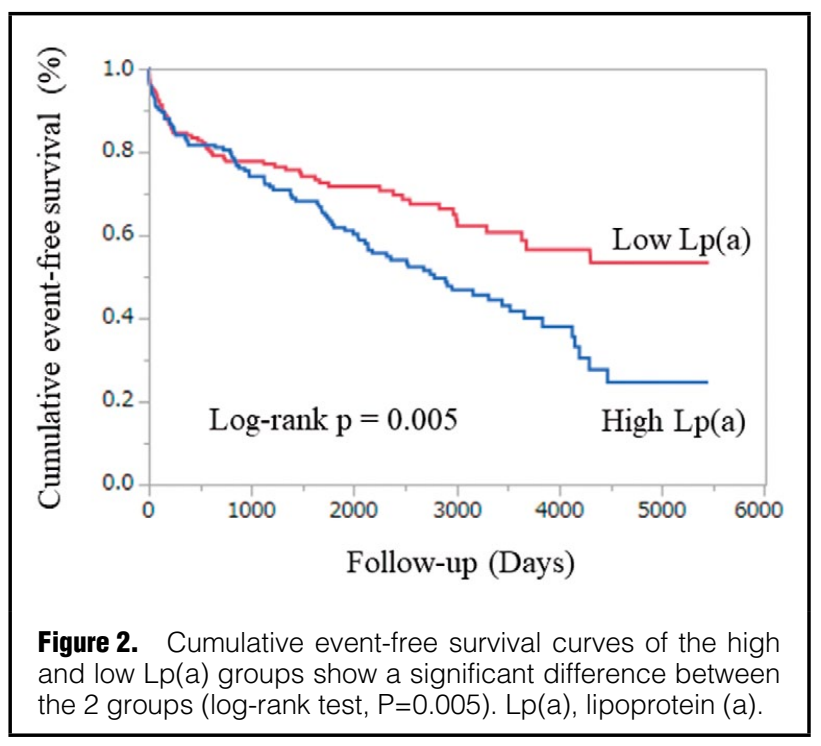

Figure 2. Cumulative event-free survival curves of the high and low Lp(a) groups show a significant difference between
the 2 groups (log-rank test, $P=0.005) . L p(a)$, lipoprotein (a). 
median Lp(a) level of $26.1 \mathrm{mg} / \mathrm{dL}$. Table 1 shows the baseline characteristics of these 369 patients. By definition, $\mathrm{Lp}(\mathrm{a})$ and LDL-C levels were significantly higher in the group with high $\mathrm{Lp}(\mathrm{a})$ than in the group with low $\mathrm{Lp}(\mathrm{a})$. No significant differences in the presence of AS was found between the 2 groups ( 9 patients in the high $\mathrm{Lp}(\mathrm{a})$ group

\begin{tabular}{|ccc|}
\hline \multicolumn{3}{|c|}{ Table 2. Event Rate of Composite Endpoint } \\
& $\begin{array}{c}\text { Low Lp(a) } \\
\text { group }\end{array}$ & $\begin{array}{c}\text { High Lp(a) } \\
\text { group }\end{array}$ \\
All-cause death, $\mathbf{n}(\%)$ & $36(23.8)$ & $44(29.1)$ \\
Cardiac death, $\mathrm{n}(\%)$ & $13(8.6)$ & $22(14.6)$ \\
HF, $\mathrm{n}(\%)$ & $7(4.6)$ & $8(14.6)$ \\
Cancer, $\mathrm{n}(\%)$ & $10(6.6)$ & $6(4.0)$ \\
Stroke, $\mathrm{n}(\%)$ & $2(1.3)$ & $2(1.3)$ \\
Infection, $\mathrm{n}(\%)$ & $3(2.0)$ & $6(4.0)$ \\
Others, $\mathrm{n}(\%)$ & $8(5.3)$ & $8(5.3)$ \\
Readmission for ACS, $\mathbf{n}(\%)$ & $11(7.3)$ & $22(14.6)$ \\
Readmission for HF, $\mathbf{n}(\%)$ & $12(8.0)$ & $26(17.2)$ \\
\hline
\end{tabular}

$\mathrm{HF}$, heart failure. Other abbreviations as $\mathrm{n}$ Table 1. vs. 5 patients in the low Lp(a) group). One patient in each group had moderate-to-severe AS. In addition, no significant differences in the other baseline characteristics were found between the groups.

The median follow-up period was 1,878 (interquartile range, 476-3,035) days, and outcome data were fully documented during the entire follow-up period. Figure 2 shows the cumulative event-free survival curves. The incidence of all-cause death or readmission for ACS or HF was significantly higher in the group of patients with high Lp(a) than in the group of patients with low Lp(a) (log-rank test, $\mathrm{P}=0.005)$. In total, $151(40.9 \%)$ clinical events were identified during follow-up, including $80(21.7 \%)$ all-cause deaths, $33(8.9 \%)$ readmissions for ACS, and $38(10.3 \%)$ readmissions for $\mathrm{HF}$. (If deaths during rehospitalization for ACS or HF occurred, those events were counted as deaths but not as readmissions for ACS or HF). The numbers and percentages of each event and cause-specific death are shown in Table 2 . Table 3 shows the univariate and multivariate Cox hazard regression analyses including variables with $\mathrm{P}<0.1$ in the univariate analysis.

In the subgroup analysis of patients with and without $\mathrm{ACS}$, the prognostic impact of $\mathrm{Lp}$ (a) level was similar

Table 3. Results of Cox Proportional Hazard Regression Analyses

\begin{tabular}{|c|c|c|c|c|c|c|}
\hline & \multicolumn{3}{|c|}{ Univariable } & \multicolumn{3}{|c|}{ Multivariable } \\
\hline & HR & $95 \% \mathrm{Cl}$ & $P$ value & HR & $95 \% \mathrm{Cl}$ & $P$ value \\
\hline Age: 1-year increase & 1.05 & $1.03-1.06$ & $<0.001$ & 1.03 & $1.01-1.05$ & $<0.001$ \\
\hline Men: yes & 0.67 & $0.44-1.05$ & 0.077 & 0.85 & $0.54-1.38$ & 0.492 \\
\hline Current smoking: yes & 0.70 & $0.47-1.01$ & 0.058 & 0.88 & $0.57-1.32$ & 0.542 \\
\hline CKD: yes & 1.62 & $1.16-2.26$ & 0.005 & 1.07 & $0.73-1.56$ & 0.715 \\
\hline Triglycerides: $1 \mathrm{mg} / \mathrm{dL}$ increase & 1.00 & $0.99-1.00$ & 0.084 & 1.00 & $0.99-1.00$ & 0.889 \\
\hline Statins use: yes & 0.70 & $0.50-0.97$ & 0.033 & 0.77 & $0.54-1.09$ & 0.137 \\
\hline Diastolic BP: $1 \mathrm{mmHg}$ increase & 0.99 & $0.97-1.00$ & 0.012 & 0.99 & $0.98-1.01$ & 0.325 \\
\hline LVEF: $1 \%$ increase & 0.97 & $0.96-0.99$ & 0.007 & 0.98 & $0.96-1.00$ & 0.016 \\
\hline Presence of aortic valve stenosis & 3.37 & $1.77-5.84$ & $<0.001$ & 2.68 & $1.38-4.75$ & 0.005 \\
\hline Lp(a) levels: high & 1.59 & $1.15-2.22$ & 0.005 & 1.54 & $1.09-2.18$ & 0.014 \\
\hline
\end{tabular}

$\mathrm{Cl}$, confidence interval; $\mathrm{HR}$, hazard ratio. Other abbreviations as $\mathrm{n}$ Table 1.

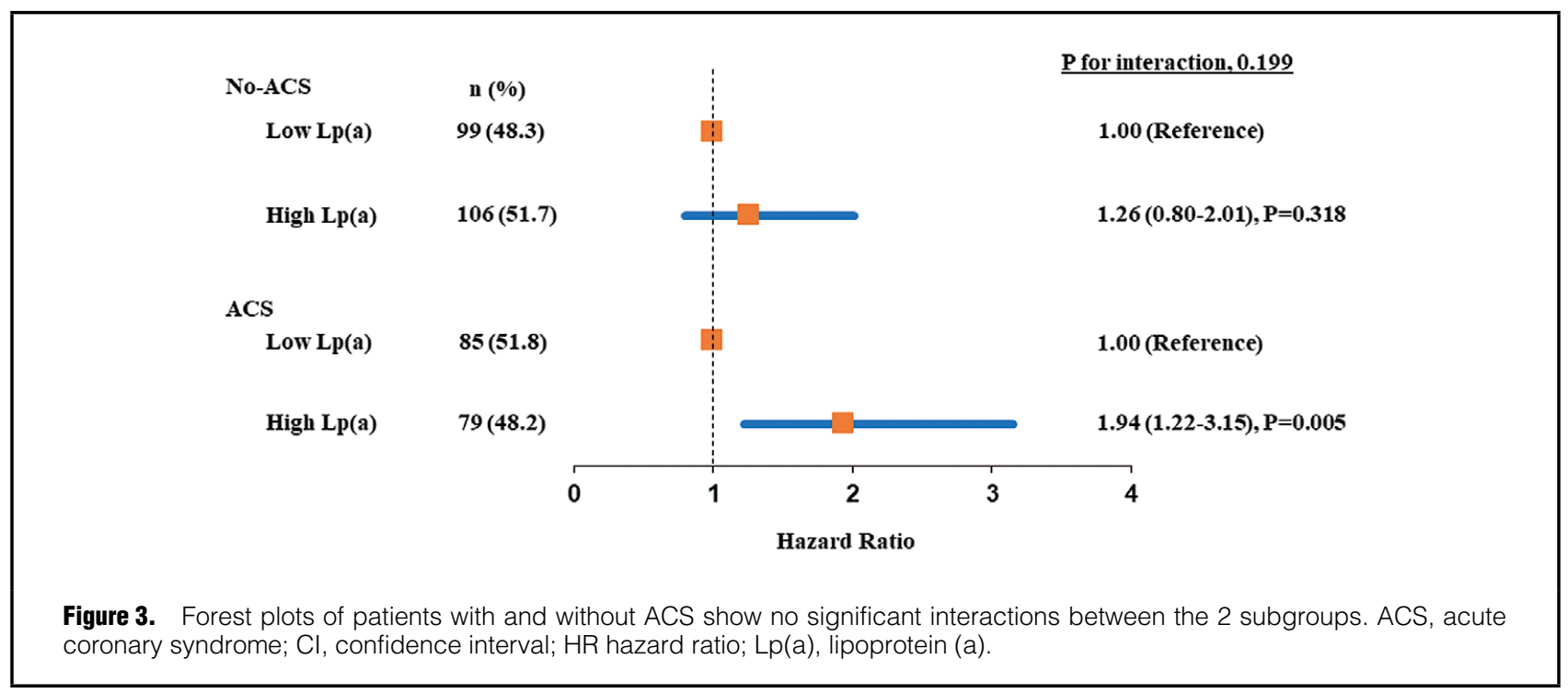


between patients with and without ACS (P for interaction, 0.199; Figure 3). Natural log-transformed Lp(a) was also associated with increased risk of clinical events in the univariable analysis (hazard ratio [HR], 1.28; 95\% confidence interval [CI], 1.05-1.57; $\mathrm{P}=0.013)$. In the multivariable Cox proportional hazards regression analysis, high $\mathrm{Lp}(\mathrm{a})$ was a significant independent predictor of unfavorable outcomes (HR, 1.54; 95\% CI, 1.09-2.18; $\mathrm{P}=0.014$ ) in addition to greater age, lower LVEF, and the presence of AS (Table 3). Secondary multivariable analysis in which high/low Lp(a) was substituted by natural log-transformed $\mathrm{Lp}(\mathrm{a})$ also showed that natural log-transformed $\mathrm{Lp}(\mathrm{a})$ as a significant independent predictor of a worse outcome (HR, 1.26; 95\% CI, 1.02-1.57; $\mathrm{P}=0.035$ ).

\section{Discussion}

The current findings are a novel insight into the relationship between $\mathrm{Lp}$ (a) levels and clinical outcomes in patients with CAD. First, a high Lp(a) level was associated with a composite of death and readmission for ACS and/or HF in patients with CAD and LV systolic dysfunction. Second, the association remained significant even after adjustment of other potential confounders. Finally, a dose-response relationship was observed between logarithm-transformed $\mathrm{Lp}$ (a) and long-term clinical outcome; the risk of clinical events increased with increasing $\mathrm{Lp}$ (a) levels. Therefore, in patients with CAD and LV systolic dysfunction, higher levels of $\mathrm{Lp}(\mathrm{a})$ were associated with a greater risk of death, incident $\mathrm{HF}$, and ACS as a predisposing condition for HF.

Previous studies have suggested that elevated Lp(a) is an independent causal risk factor for cardiovascular disease. ${ }^{23-25}$ Kamstrup et al, in the Copenhagen City Heart Study, showed that high levels of $\mathrm{Lp}(\mathrm{a})$ were associated with an increased risk of MI. ${ }^{26} \mathrm{~A}$ meta-analysis of populationbased studies and studies involving patients with diabetes, kidney disease, and pre-existing CAD also showed the association between elevated $\mathrm{Lp}(\mathrm{a})$, and increased risk of CADrelated deaths and non-fatal MI, both in primary and secondary prevention cohorts. ${ }^{27}$ Our group reported that $\mathrm{Lp}$ (a) levels can predict cardiovascular events in CAD patients who have diabetes ${ }^{28}$ or $\mathrm{CKD},{ }^{29}$ or those who are undergoing statin treatment. ${ }^{30}$ Taken together, there is a clear association between $\mathrm{Lp}$ (a) levels and the morbidity and mortality of CAD in patients, and, among those with comorbidities, in both primary and secondary prevention cohorts.

A recent report from the Copenhagen City Heart Study in conjunction with the Copenhagen General Population Study showed that increased $\mathrm{Lp}$ (a) levels were associated with an increased risk of HF in 98,097 normal individuals. ${ }^{15}$ That study reported that the association of $\mathrm{Lp}(\mathrm{a})$ and incident $\mathrm{HF}$ appeared to be partly mediated by MI and AS. The study showed a significant association between $\mathrm{Lp}(\mathrm{a})$ and HF even after exclusion of participants with previous diagnoses of MI and AS, suggesting that Lp(a) may increase incident HF through other mechanisms. For instance, high $\mathrm{Lp}(\mathrm{a})$ levels may possibly lead to increased arterial stiffness and vascular noncompliance, which will increase afterload and have been associated with an increased risk of HF. In fact, Sorokin et al showed a positive association between $\mathrm{Lp}$ (a) and arterial stiffness parameters; that is, increased $\mathrm{Lp}$ (a) levels were associated with greater stiffness. ${ }^{31}$ This process leads to hypertension, finally resulting in LV hypertrophy or fibrosis, which could cause systolic or diastolic LV dysfunction. In particular, because the failing heart is sensitive to increased afterload, ${ }^{32}$ this mechanism may be more prominent in patients with LV systolic dysfunction. However, very few clinical studies have been conducted to evaluate the relationship between $\mathrm{Lp}(\mathrm{a})$ and the incidence of HF in patients with LV systolic dysfunction. In the present study, we evaluated the association between $\mathrm{Lp}$ (a) levels and readmission for HF or ACS as a predisposing condition for HF, in addition to all-cause death, some of which may be related to HF in patients with CAD and LV systolic dysfunction. We observed that differences in the specific causes of clinical events between high and low Lp(a) levels were more obvious in terms of readmission for $\mathrm{HF}$ (Table 2). These findings suggested that the $\mathrm{Lp}(\mathrm{a})$ level has an impact on prognosis and could be a useful biomarker for risk stratification in patients with CAD and LV systolic dysfunction. Further studies are warranted to elucidate the mechanism of association between $\mathrm{Lp}$ (a) level and the incidence of HF, and to determine whether lowering the Lp(a) level by a specific intervention may improve prognosis in patients with CAD and LV dysfunction.

Serum levels of $\mathrm{Lp}(\mathrm{a})$ are genetically determined; $>90 \%$ of the variance in $\mathrm{Lp}(\mathrm{a})$ concentration can be attributed to genetics, and it cannot be altered by diet or exercise. ${ }^{33}$ Kamstrup et al also reported an association between highrisk genetic variants in the LPA gene (rs3798220 and rs10455872) and incident HF in the Copenhagen study. ${ }^{15}$ Although no specific pharmacotherapy can reduce the Lp(a) level, several drugs, such as fibrates, nicotinic acid, and aspirin, have been reported as effective in reducing Lp(a) levels. ${ }^{34-36}$ Furthermore, some new lipid-lowering drugs can reduce $\mathrm{Lp}(\mathrm{a})$ levels. Cannon et al reported that anacetrapib decreased $\mathrm{Lp}(\mathrm{a})$ levels by $38 \%$ after 76 weeks. ${ }^{37}$ In the Randomized Evaluation of the Effects of Anacetrapib through Lipid Modification (REVEAL) trial, it was reported that the mean level of $L p(a)$ was lower by $15 \mathrm{nmol} / \mathrm{L}$ in the anacetrapib group than in the placebo group. ${ }^{38}$ Another new drug is a proprotein convertase subtilisin/kexin 9 inhibitor, which also decreased $\mathrm{Lp}(\mathrm{a})$ levels by $10-30 \%$ after 12 weeks. ${ }^{39}$ Furthermore, evolocumab reduced $L p(a)$ levels by $26.9 \%{ }^{40}$ If reduction of the $L p(a)$ level by these drugs could improve long-term outcomes, the causality of the relationship between increased $\mathrm{Lp}(\mathrm{a})$ levels and clinical outcome could be proven.

\section{Study Limitations}

First, our study was limited to a single academic center and involved only a Japanese patient population. The association between $\mathrm{Lp}$ (a) levels and long-term outcomes in patients with CAD and LV systolic dysfunction needs to be examined in a larger sample size. Second, because the present study was observational in nature, even after the adjusted analysis, other confounders affecting the results cannot be ruled out. Moreover, whether high Lp(a) levels are just a marker of poor long-term outcome or a potential therapeutic target remains unclear. Third, Lp(a) levels have been reported as possibly increased in the acute phase of ACS or after PCI. In our study, even though all blood sampling timing occurred early in the morning after an overnight fast, some sampling data were collected in the acute phase. Therefore, the effects of $\mathrm{Lp}(\mathrm{a})$ level on clinical outcomes might differ between patients with and without ACS. However, the differences in the timing of blood sampling between patients with and without ACS might have no effect on clinical outcomes because no significant interaction was observed between the presentation of ACS and 
the $\mathrm{Lp}$ (a) level/clinical outcome relationship. Fourth, $\mathrm{Lp}$ (a) levels are affected by apo (a) phenotype. ${ }^{41}$ Therefore, considering this, the results of the present study should be interpreted with caution. Despite these limitations, our study highlighted that high Lp(a) levels are associated with an increased risk of death, incident HF, and incident ACS, which is a predisposing condition for HF, in patients with CAD and LV systolic dysfunction.

\section{Conclusions}

Increased Lp(a) levels were significantly associated with poor long-term clinical outcomes among patients with CAD and LV dysfunction.

\section{Acknowledgments}

We thank the staff of the Department of Cardiovascular Medicine at Juntendo University. We are also grateful to Yumi Nozawa and Ayako Onodera for their secretarial assistance.

\section{Financial / Nonfinancial Disclosures}

This study was partly supported by a Grant-in-Aid for Scientific Research (C) [Grant no. 26507010]; a grant to the Respiratory Failure Research Group from the Ministry of Health, Labor and Welfare of Japan; and a Health, Labor and Welfare Sciences Research Grant, Research on Region Medical from the Ministry of Health, Labor and Welfare of Japan. Dr. Kasai is affiliated with a department endowed by Philips Respironics, ResMed, Teijin Home Healthcare, and Fukuda Denshi. Dr. Daida received speakers' Bureau/Honoraria from Kowa Pharmaceutical Company Ltd., Sanofi-Aventis K.K., Daiichi Sankyo Company, Takeda Pharma ceutical Co., Ltd., Bayer Yakuhin Ltd., MSD K.K., Astellas Pharma Inc., Amgen Astellas BioPharma K.K., AstraZeneca K.K., and research funds from Sanwakagaku Kenkyusho Co., Ltd., Canon Medical Systems Corporation., Kowa Pharmaceutical Company Ltd., Daiichi Sankyo Company., Abbott Medical Japan Co., Ltd., Nihon Medi-Physics Co., Ltd., and Scholarship funds from Abbott Medical Japan Co., Ltd., Nippon Boehringer Ingelheim Co., Ltd., Otsuka Pharmaceutical Co., Ltd., Bayer Yakuhin Ltd., Astellas Pharma Inc., Dainippon Sumitomo Pharma Co., Ltd., Pfizer Co., Ltd., Daiichi Sankyo Company., Takeda Pharma ceutical Co., Ltd., Abbott Medical Japan Co., Ltd., Actelion Pharmaceuticals Ltd., Mitsubishi Tanabe Pharma Corporation., Teijin Pharma Ltd., that are unrelated to this study. All other authors declare no conflicts of interest.

\section{Role of the Sponsors}

These funding sources have no other roles in this study. The sponsor had no role in the design of the study, the collection and analysis of the data, or the preparation of the manuscript.

\section{References}

1. Okura Y, Ramadan MM, Ohno Y, Mitsuma W, Tanaka K, Ito M, et al. Impending epidemic: Future projection of heart failure in Japan to the year 2055. Circ J 2008; 72: 489-491.

2. McGovern PG, Jacobs DR Jr, Shahar E, Arnett DK, Folsom $\mathrm{AR}$, Blackburn H, et al. Trends in acute coronary heart disease mortality, morbidity, and medical care from 1985 through 1997: The Minnesota Heart Survey. Circulation 2001; 104: 19-24.

3. Randomised trial of cholesterol lowering in 4444 patients with coronary heart disease: The Scandinavian Simvastatin Survival Study (4S). Lancet 1994; 344: 1383-1389.

4. Kwok CS, Rao SV, Gilchrist I, Martinez SC, Al Ayoubi F, Potts $\mathrm{J}$, et al. Relation between age and unplanned readmissions after percutaneous coronary intervention (findings from the Nationwide Readmission Database). Am J Cardiol 2018; 122: 220-228.

5. Lamblin N, Meurice T, Tricot O, Lemesle G, Deneve M, de Groote $\mathrm{P}$, et al. Effect of left ventricular systolic dysfunction on secondary medical prevention and clinical outcome in stable coronary artery disease patients. Arch Cardiovasc Dis 2017; 110: 35-41.

6. Burns RJ, Gibbons RJ, Yi Q, Roberts RS, Miller TD, Schaer GL, et al. The relationships of left ventricular ejection fraction, end-systolic volume index and infarct size to six-month mortality after hospital discharge following myocardial infarction treated by thrombolysis. J Am Coll Cardiol 2002; 39: 30-36.
7. Flaherty JD, Bax JJ, De Luca L, Rossi JS, Davidson CJ, Filippatos G, et al. Acute heart failure syndromes in patients with coronary artery disease early assessment and treatment. $\mathrm{J} \mathrm{Am}$ Coll Cardiol 2009; 53: 254-263.

8. Driscoll A, Barnes EH, Blankenberg S, Colquhoun DM, Hunt $\mathrm{D}$, Nestel PJ, et al. Predictors of incident heart failure in patients after an acute coronary syndrome: The LIPID heart failure riskprediction model. Int J Cardiol 2017; 248: 361-368.

9. Daida H, Miyauchi K, Ogawa H, Yokoi H, Matsumoto M, Kitakaze M, et al. Management and two-year long-term clinical outcome of acute coronary syndrome in Japan: Prevention of atherothrombotic incidents following ischemic coronary attack (PACIFIC) registry. Circ J 2013; 77: 934-943.

10. Steyrer E, Durovic S, Frank S, Giessauf W, Burger A, Dieplinger $\mathrm{H}$, et al. The role of lecithin:cholesterol acyltransferase for lipoprotein (a) assembly: Structural integrity of low density lipoproteins is a prerequisite for $\mathrm{Lp}(\mathrm{a})$ formation in human plasma. $J$ Clin Invest 1994; 94: 2330-2340.

11. Ikenaga H, Ishihara M, Inoue I, Kawagoe T, Shimatani Y, Miura $\mathrm{F}$, et al. Usefulness of lipoprotein (a) for predicting progression of non-culprit coronary lesions after acute myocardial infarction. Circ J 2011; 75: 2847-2852.

12. Kardys I, Oemrawsingh RM, Kay IP, Jones GT, McCormick SP, Daemen J, et al. Lipoprotein(a), interleukin-10, C-reactive protein, and 8-year outcome after percutaneous coronary intervention. Clin Cardiol 2012; 35: 482-489.

13. Kamstrup PR, Tybjaerg-Hansen A, Nordestgaard BG. Elevated lipoprotein(a) and risk of aortic valve stenosis in the general population. J Am Coll Cardiol 2014; 63: 470-477.

14. Arsenault BJ, Boekholdt SM, Dube MP, Rheaume E, Wareham NJ, Khaw KT, et al. Lipoprotein(a) levels, genotype, and incident aortic valve stenosis: A prospective Mendelian randomization study and replication in a case-control cohort. Circ Cardiovasc Genet 2014; 7: 304-310.

15. Kamstrup PR, Nordestgaard BG. Elevated lipoprotein(a) levels, LPA risk genotypes, and increased risk of heart failure in the general population. JACC Heart Fail 2016; 4: 78-87.

16. Konishi H, Miyauchi K, Kasai T, Tsuboi S, Ogita M, Naito R, et al. Impact of lipoprotein(a) as residual risk on long-term outcomes in patients after percutaneous coronary intervention. $\mathrm{Am}$ J Cardiol 2015; 115: 157-160.

17. Kronenberg F, Utermann G, Dieplinger H. Lipoprotein(a) in renal disease. Am J Kidney Dis 1996; 27: 1-25.

18. Matsuo S, Imai E, Horio M, Yasuda Y, Tomita K, Nitta K, et al. Revised equations for estimated GFR from serum creatinine in Japan. Am J Kidney Dis 2009; 53: 982-992.

19. Thygesen K, Alpert JS, White HD. Universal definition of myocardial infarction. Eur Heart J 2007; 28: 2525-2538.

20. Jaffe AS, Ravkilde J, Roberts R, Naslund U, Apple FS, Galvani $\mathrm{M}$, et al. It's time for a change to a troponin standard. Circulation 2000; 102: $1216-1220$.

21. Cannon CP, Brindis RG, Chaitman BR, Cohen DJ, Cross JT Jr, Drozda JP Jr, et al. 2013 ACCF/AHA key data elements and definitions for measuring the clinical management and outcomes of patients with acute coronary syndromes and coronary artery disease: A report of the American College of Cardiology Foundation/American Heart Association Task Force on Clinical Data Standards (Writing Committee to Develop Acute Coronary Syndromes and Coronary Artery Disease Clinical Data Standards). Circulation 2013; 127: 1052-1089.

22. Gheorghiade M, Pang PS. Acute heart failure syndromes. $J A m$ Coll Cardiol 2009; 53: 557-573.

23. Erqou S, Kaptoge S, Perry PL, Di Angelantonio E, Thompson A, White IR, et al. Lipoprotein(a) concentration and the risk of coronary heart disease, stroke, and nonvascular mortality. JAMA 2009; 302: 412-423.

24. Waldeyer C, Makarova N, Zeller T, Schnabel RB, Brunner FJ, Jorgensen T, et al. Lipoprotein(a) and the risk of cardiovascular disease in the European population: Results from the BiomarCaRE consortium. Eur Heart J 2017; 38: 2490-2498.

25. Tsimikas S, Brilakis ES, Miller ER, McConnell JP, Lennon RJ, Kornman KS, et al. Oxidized phospholipids, Lp(a) lipoprotein, and coronary artery disease. N Engl J Med 2005; 353: 46-57.

26. Kamstrup PR, Tybjaerg-Hansen A, Steffensen R, Nordestgaard BG. Genetically elevated lipoprotein(a) and increased risk of myocardial infarction. JAMA 2009; 301: 2331-2339.

27. Danesh J, Collins R, Peto R. Lipoprotein(a) and coronary heart disease: Meta-analysis of prospective studies. Circulation 2000; 102: $1082-1085$.

28. Konishi H, Miyauchi K, Shitara J, Endo H, Wada H, Doi S, et al. 
Impact of lipoprotein(a) on long-term outcomes in patients with diabetes mellitus who underwent percutaneous coronary intervention. Am J Cardiol 2016; 118: 1781-1785.

29. Konishi H, Miyauchi K, Tsuboi S, Ogita M, Naito R, Dohi T, et al. Plasma lipoprotein(a) predicts major cardiovascular events in patients with chronic kidney disease who undergo percutaneous coronary intervention. Int J Cardiol 2016; 205: 50-53.

30. Suwa S, Ogita M, Miyauchi K, Sonoda T, Konishi H, Tsuboi S, et al. Impact of lipoprotein (a) on long-term outcomes in patients with coronary artery disease treated with statin after a first percutaneous coronary intervention. J Atheroscler Thromb 2017; 24: $1125-1131$

31. Sorokin A, Kotani K. Lipoprotein(a) and arterial stiffness parameters. Pulse (Basel) 2015; 3: 148-152.

32. Ross J Jr. Afterload mismatch and preload reserve: A conceptual framework for the analysis of ventricular function. Prog Cardiovasc Dis 1976; 18: 255-264.

33. Boerwinkle E, Leffert CC, Lin J, Lackner C, Chiesa G, Hobbs $\mathrm{HH}$. Apolipoprotein(a) gene accounts for greater than $90 \%$ of the variation in plasma lipoprotein(a) concentrations. J Clin Invest 1992; 90: 52-60.

34. Lippi G, Targher G. Optimal therapy for reduction of lipoprotein(a). J Clin Pharm Ther 2012; 37: 1-3.

35. Jacobson TA. Lipoprotein(a), cardiovascular disease, and contemporary management. Mayo Clin Proc 2013; 88: 1294-1311.

36. Sahebkar A, Simental-Mendia LE, Watts GF, Serban MC, Banach
M. Comparison of the effects of fibrates versus statins on plasma lipoprotein(a) concentrations: A systematic review and metaanalysis of head-to-head randomized controlled trials. BMC Med 2017; 15: 22.

37. Cannon CP, Shah S, Dansky HM, Davidson M, Brinton EA, Gotto AM, et al. Safety of anacetrapib in patients with or at high risk for coronary heart disease. $N$ Engl J Med 2010; 363: 24062415.

38. Bowman L, Hopewell JC, Chen F, Wallendszus K, Stevens W, Collins R, et al. Effects of anacetrapib in patients with atherosclerotic vascular disease. $N$ Engl J Med 2017; 377: 1217-1227.

39. McKenney JM, Koren MJ, Kereiakes DJ, Hanotin C, Ferrand AC, Stein EA. Safety and efficacy of a monoclonal antibody to proprotein convertase subtilisin/kexin type 9 serine protease, SAR236553/REGN727, in patients with primary hypercholesterolemia receiving ongoing stable atorvastatin therapy. $\mathrm{J} \mathrm{Am} \mathrm{Coll}$ Cardiol 2012; 59: 2344-2353.

40. Sabatine MS, Giugliano RP, Keech AC, Honarpour N, Wiviott $\mathrm{SD}$, Murphy SA, et al. Evolocumab and clinical outcomes in patients with cardiovascular disease. N Engl J Med 2017; 376: $1713-1722$.

41. Orisaka M, Koyamada K, Saika Y, Sakurabayashi I. Reference values of plasma lipoprotein (a) in newly classified apolipoprotein(a) phenotype groups in the Japanese population. Ann Clin Biochem 2000; 37: 701-707. 